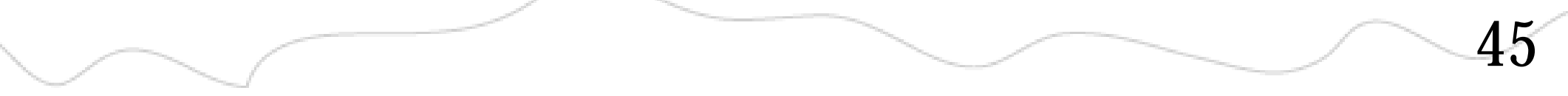

\title{
One University's Approach to an Outcome-Based Teacher Education Program
}

\author{
Robert A. Raudebaugh
}

Since the early 1980s, there has been increasing pressure from both the media and politicians to make major changes in the educational system in America. The impetus for this movement came primarily from the reports of 1983 which led the American public and politicians to believe that our schools were in serious trouble, particularly when compared to those in Europe and Japan. The agitation for educational reform which ensued led to the establishment of more rigorous standards for schools. Eventually the state of Washington enacted the "Washington Educational Reform Act of 1993."

Colleges and universities in Washington are now required to adhere to new standards for teacher preparation. The first of these new standards to be written and adopted was in the area of vocational teacher preparation, which includes technology education. Given no choice in the matter, the questions became, How do we do it? and Can we make it work?

The first step in developing outcome-based curricula was to determine specifically what the outcomes should be. That began with defining what new teachers need to know and what they need to be able to do (teaching tasks) to be successful. Since teaching excellence evolves over a period of many years, the development of teacher education curricula should focus on the skills most needed during internships and the first year.

The technology teacher education program at Western Washington University (WWU) is divided into four content areas: (a) content for technical breadth, (b) content for technical depth, (c) supporting math and science content, and (d) professional or pedagogical content. The process described in this article was limited to the development of (d) the professional content.

\section{Identification of Teacher Tasks/Competencies}

In 1991, staff of the Washington Center for Vocational Educator Preparation (WCVEP), including this author, conducted research into the duties, tasks, and competencies related to vocational education, many of which are also related to technology education. A variety of materials were used to identify the tasks including the following:

- The Ohio State University Center for Vocational Education modules.

- Vocational Education Consortia of the States (VECS) modules.

- American Society for Training and Development (ASTD) modules.

- State modules from Florida, Illinois, and Massachusetts.

- Units of instruction for vocational teacher preparation for the state of Washington.

These materials yielded a list of approximately 175 teaching tasks which resulted in surveys administered to vocational teachers and administrators throughout the state. The feedback was used to develop a prioritized list of 80 vocational teacher competencies.

From this competency list and other industrial arts teacher training materials at WWU, a list of competencies for beginning technology education teachers was created. In 1993, this competency list was submitted in survey form to 64 practicing technology teachers and administrators for verification and validation. (The survey participants were selected on the basis of their involvement in the technology education reform movement.) The results were analyzed and used in further developing materials for the professional course structure 
for technology education at WWU implemented in the spring quarters of 1994 through 1997. To validate competencies in these new areas, a panel of experts identified tasks missing from the current list but required to meet new standards. The panel consisted of the state supervisor for TSA, the executive secretary of the Washington Technology Education Association, and two teachers from local high schools actively engaged in developing technology education programs and in working with student interns. The problem identified at the beginning of the procedure was to determine what effective teachers need to do to work with implementing tech prep and school-to-career concepts, and how to incorporate quality student leadership activities into technology education programs.

The 1997 survey report and the work of the panel of experts were analyzed and the results were incorporated into a final competency list. During the process of determining which competencies belonged to which course, many teaching tasks were reorganized into more coherent groupings under new competency statements. The competencies were then incorporated into the five existing courses making up the professional component of the program.

\section{Development of Instructional Strategies}

Development of the outcomes and their organization into a course structure was followed by the selection of the effective learning strategies that would aid students of differing learning styles to successfully reach the desired outcomes. Before instruction began, students were presented with the course competency requirements and informed of the process used to develop them. By so doing, students were found to be more accepting of the competencies and performance standards and the methods used for instruction.

All too frequently teacher educators use a "do as I say, not as I do" approach to methodology in teacher education courses. In order to be effective, teacher educators need to model the behaviors that they expect teacher candidates to eventually use in their classrooms and laboratories, and these classroom behaviors should be incorporated into the learning strategies used for an outcomebased approach to instruction.

General skills (including problem solving, teamwork, and collaboration), such as those recommended in the SCANS Report (1992), and independent information gathering and learning skills were incorporated into the program by including them as part of the instructional strategies. Students saw connections among and interactions of various content areas (i.e., history and philosophy, safety instruction, curriculum, methods, school-towork transition, and student leadership) by organizing the courses into a concurrent block. Utilizing the strategy of cross-disciplinary techniques allow candidates the opportunity to observe good teaching. At WWU, the guiding principles for development and implementation of the instructional strategies are based on recommendations from the Council on Technology Teacher Education (Henak, 1991), which follow:

In order to realize the full potential from experimental learning in Technology, teacher education implementers need to:

1. View students as active self-directed learners and treat them more like colleagues than as receivers of lectures, assignments, and grades.

2. Include the processes used in technical systems to apply knowledge, discover new knowledge, solve problems, and learn from mistakes.

3. Extend the purpose for technology to go beyond the awareness and understanding levels, and enter into the application and problem solving levels of thinking.

4. Create environments where students encounter more authentic problem-centered experiences in simulated or real industrial/environmental settings and apply the heuristic method practiced by professionals in the field.

5. Reduce individual and competitive learning environments and increase the use of collabo rative group learning experiences in which heterogeneous teams are created, leadership is distributed, positive interdependence is present, and social skills are acquired within an autonomous group.

6. Change the structure and approach of technology teacher education curricula from subject-based and teacher-directed to problem-based and student-directed, because 


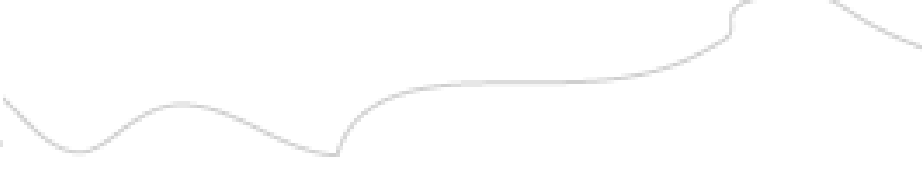

teaching activity is not experienced as subjects. Instead, teaching activity consists of a series of problems that need to be solved. (p. 3)

A design activity is presented to the students at the beginning of the block. Students must either design/develop a unit of instruction individually or work in a team to develop an entire course. An instructional systems design approach is used for this purpose. The unit/course content they develop must be stated as learning outcomes. Appropriate instructional strategies, learning activities, and resources must accompany each outcome. Assessment strategies are developed that will allow both students and the instructor to know when the designated content outcomes have been met. An instructional management system is developed that tracks the instructional process, reflects student progress, and incorporates the philosophy of the instructor. Safety instruction, tech prep, and school-to-work outcomes and student leadership skill development must be reflected in the content and methods developed. This curriculum design activity becomes the focus for the development of virtually all the competencies of the five professional courses in the block. This way, students get a holistic view of the process and learn to align the various components of a quality program.

\section{Development and Identification of Instructional Resources}

At WWU, a variety of resources have been identified in sufficient quantities so that students will be able to complete most learning activities without reliance upon the instructor's knowledge. Learning resource materials provide students with choices and accommodate variation in learning styles. The acquisition of some resource material has been made the responsibility of the students in the class both independently and in student teams and as a joint effort between students and faculty. However, most of the resources required to meet the competencies are available prior to the beginning of the class. At WWU, these materials include the following types:

- Field trip visitations.

- Guest speakers.

- Professional journals.

- Internet sites.

- Computer-based instructional materials.

- Tutorials (instructor and student developed and commercial).

- Collection of existing curriculum materials.

- Previous student projects and other work.

- Catalogs and examples of commercially developed materials.

- Materials from professional associations, both state and national.

- Experts in the field including teachers, administrators, and others.

- Texts and other reference books.

\section{Development of Assessment Strategies}

The purpose and process of assessment is often confused with the process of grading. Grading is for the purpose of assigning a letter grade, usually based on some numerical data gathered through assignments, quizzes, and exams. Frequently this process is used as a source of motivation to influence students to "produce" the appropriate feedback required by these assignments, quizzes, and exams. Seldom does it provide accurate data on what skills and knowledge students may have actually learned as a result of instruction.

The true measurement of competency acquisition is found in the concept of authentic assessment; that is, accurately measuring competency attainment. For example, if a student competency is to develop learning activitites, then students develop activities according to specified quality standards. The assessment is a comparison of the student's work to those standards rather than a quiz on activity development. In teacher preparation, the object of this process is for both the instructor and the student to know when the student is capable of carrying out a specific teaching task. Authentic assessment also incorporates appropriate quality standards for task performance, in this case, the skill expected of a student intern or beginning teacher.

Authentic assessment seldom includes the traditional objective-type tests, although it does not altogether rule them out. At WWU, competency performance is sometimes observed and often involves a product. Both conditions are measured to determine if the performance or the product meets agreed-upon standards. It is not expected that a student achieve the quality standard on the first attempt; therefore, frequent and appropriate feedback is provided from both the instructor and peers as 
the students work through the activities. Students also have ample opportunity for self-evaluation.

\section{Managing the Instructional Process}

The philosophy of the faculty at WWU is that completion of all competencies at the required quality standard is within the capability of every student in the class. To accomplish this, however, takes planning on the part of both the instructor and the students, both individually and collectively. Students are allowed to work on each competency until that standard is met. This requires selfassessment and peer-assessment strategies; final assessment is the responsibility of the instructor.

The question of grading is always on the minds of students at the beginning of the block. They have been well conditioned to think of grades accompanying GPAs. If appropriate standards have been set for each competency and the student meets those standards, then the only grade possible is an "A." The question is, What happens when the student does not meet the standard settled on the first day of class? Several options are discussed including arriving at some lesser grade, either at the discretion of the faculty or in consultation with the student, or assuming the work is still in progress and awarding an "Incomplete."

The entire process requires students to submit work on a continuous basis for feedback. It is important that students understand that they should make a strong effort before initially submitting work, but that the first attempt is not the final evaluation. The process involves making continual progress until the prescribed standard is met.

Some students do better work, do it faster, and do more of it. It is not the point of authentic assessment, however, to distinguish between students' achievement rates, unless competition among students is considered a desired outcome. Care should be taken to not discriminate against individual conditions and style. If the competency is met at the required standard, then allowances can be made for individual style factors. It is possible for biases and personalities to creep into the process at this point.

The management system takes into consideration all of these issues. Its main purpose is as a planning tool to assist students in planning and evaluating their work. It also provides a record for instructors and incorporates opportunities for instructor feedback. At WWU, the instructional management system incorporates the following characteristics:

- Students and instructor establish a plan for completing the competencies, which includes a schedule for the following:

- Field and guest speaker schedules.

- Tentative work deadlines.

- Class discussions.

- Final assessment deadlines.

- Provisions are made for teaming, collaboration, and cooperative learning.

- A student self-assessment procedure is developed.

- Peer assessment procedures are developed.

- Appropriate feedback is provided.

- Student progress is tracked on a spreadsheet and made available to students.

- Total quality learning principles are utilized including student development of mission and vision statements and a code of conduct.

- Students are given opportunity to make recommendations for quality improvement.

- Students are involved in the process.

The management system also sets the tone for the class. In this process, the instructor acts more as a facilitator or coach rather than a lecturer and controller. Students have more say in the process, with respect and trust being the most common factors.

\section{Evaluation of Program Effectiveness}

The final step in the process-one critical for improvement-is the continuous evaluation of program effectiveness. The best source of information for this is the students. They know when they are learning or if they are not learning. The traditional evaluation of teaching procedures found on many university campuses is mostly designed around issues of promotion, tenure, and merit, which may not be appropriate for measuring the effectiveness of a program. Much of the evaluation work will be incorporated into establishing the competencies in the first place. Materials must be updated periodically. It is also important to collaborate with other faculty in the process in order to share and discuss different ideas. Program evaluation activities can include the following:

- Student evaluations of teaching. 
- Follow-up/supervision of student interns.

- Follow-up of program graduates.

- Constant review of the literature (including presentations and publications).

- Continual feedback from students.

- Total quality improvement materials/techniques.

- Periodic competency validation surveys.

All of these procedures are used at WWU. Feedback from students, teachers and administrators in the field, and other faculty, and an ongoing review of relevant literature indicate that the process is working. Extensive revisions to the program were made in the summer of 1997 through a summer teaching grant, and further evaluation will take place to measure any improvements gained.

This article reflects only one approach to improving technology teacher education and incorporating an outcome- or competency-based model. During the last two years at WWU, the students have chosen to develop an entire course as a class project for fulfilling the competencies. The feedback from these classes and the resulting work indicate that not only is the process working, but that the results are far superior to those attained when the courses were taught in a more traditional mode. As these students become teachers, the effectiveness of the approach will truly surface. Current evidence suggests, however, that at the very least, these students are far more enthusiastic about teaching and far better prepared for their employment interviews than previous students.

Dr. Robert A. Raudebaugh is an associate professor of technology education and director of graduate studies in technology education in the Engineering Technology Department at Western Washington University, Bellingham. He is also a member of Delta Field chapter of Epsilon Pi Tau.

\section{References}

Henak, R. (1991). Elements and structure for a model undergraduate technology teacher education program (CTTE Monograph 11). Reston, VA: CTTE.

The Secretary's Commission on Achieving Necessary Skills Report. (1992). What work requires of schools.

WA: Washington Technology Education Association.

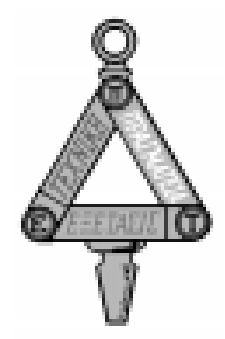

